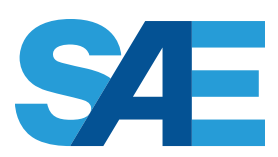

INTERNATIONAL。

\title{
Effect of Timing and Location of Hotspot on Super Knock during Pre-ignition
}

2017-01-0686

Published 03/28/2017

\section{Mohammed Jaasim Mubarak Ali, Francisco Hernandez Perez, S. Vedharaj, R. Vallinayagam, Robert Dibble, and Hong Im}

King Abdullah University of Science and Technology

CITATION: Mubarak Ali, M., Hernandez Perez, F., Vedharaj, S., Vallinayagam, R. et al., "Effect of Timing and Location of Hotspot on Super Knock during Pre-ignition," SAE Technical Paper 2017-01-0686, 2017, doi:10.4271/2017-01-0686.

Copyright (C) 2017 SAE International

\begin{abstract}
Pre-ignition in SI engine is a critical issue that needs addressing as it may lead to super knock event. It is widely accepted that pre-ignition event emanates from hot spot(s) that can be anywhere inside the combustion chamber. The location and timing of hotspot is expected to influence the knock intensity from a pre-ignition event. In this study, we study the effect of location and timing of hot spot inside the combustion chamber using numerical simulations. The simulation is performed using a three-dimensional computational fluid dynamics (CFD) code, CONVERGETM. We simulate 3-D engine geometry coupled with chemistry, turbulence and moving structures (valves, piston). G-equation model for flame tracking coupled with multi-zone model is utilized to capture auto-ignition (knock) and solve gas phase kinetics. A parametric study on the effect of hot spot timing and location inside the combustion chamber is performed. The hot spot timing considered are $-180 \mathrm{CAD},-90 \mathrm{CAD}$ and $-30 \mathrm{CAD}$ and the locations of the hot spots are in the center and two edges of the piston surfaces. Simulation results for normal combustion cycle are validated against the experimental data. The simulation results show great sensitivity to the hot spot timing, and the influence of local temperature gradient is noted to be significant. In case of early hot spot timing of $-180 \mathrm{CAD}$, the pre-ignition event did not lead to super knock. Nevertheless, at late hot spot timing, super knock was realized. On the other hand, the effect of hot spot location on pre-ignition event depends on the geometry of the combustion chamber.
\end{abstract}

\section{Introduction}

In modern spark ignition (SI) engines, down sizing and boosting are the means to achieve improved performance and reduced fuel consumption $[\underline{1}, \underline{2}]$. Nonetheless, the improved performance is obstructed by engine knock, which is the auto-ignition of end gas that results in an audible sound, called "knock" or "ping" $[\underline{3}, \underline{4}, \underline{5}, \underline{6}, \underline{7}]$. Sustained knock damages the engine, given the pressure oscillation with higher amplitude are transmitted through engine structure [ $\underline{8}]$. Various knock suppression methods $[\underline{9}, \underline{10}, \underline{11}, \underline{12}, \underline{13}]$ are developed over the years, such as cooled exhaust gas recirculation, direct injection of fuel into cylinder, multiple fuel injections and variable valve timing $[\underline{14}, \underline{15}, \underline{16}]$. Alternatively, one seeks fuels that are less prone to auto-ignition. Thus, knock is a problem that is interrelated to engine design, engine operation and fuel. Should a flame start before the spark ignition, we have phenomena called "pre-ignition". A pre-ignition event produces end gas, just like a spark ignition event. When pre-ignition is early, the end gas can explode near TDC resulting in a knock event of greater pressure rise. The most vulnerable part during pre-ignition event is the piston, piston rings and valves that are more prone to damage due to excessive momentary pressure buildup during the pre-ignition event that leads to super-knock $[\underline{17}, \underline{18}]$.

The factors that influence development of pre-ignition during the compression stroke are studied recently. Multiple auto-ignitions inside cylinder may be observed during the pre-ignition event. Pre-ignition in SI engines are well reported in literature $[\underline{17}, \underline{18}, \underline{19}$, $\underline{20}, \underline{21}, \underline{22}]$ and methods to suppress the pre-ignition that may lead to super-knock is also suggested in literature [18]. Origin of pre-ignition inside engines through optical measurements is also reported [19]. Engine oil droplets and oil composition play a major role in influencing the pre-ignition and flame initiation [19]. Characterization of pre-ignition due to engine oil droplets has been studied widely and reported in literature $[\underline{20}, \underline{21}, \underline{22}]$. Composition of the lubricity additive in the engine oil is often identified as another major source of pre-ignition.

There is a vast amount of literature, spanning 100 years, reporting the findings of numerous experiments. Methods that model this interplay are highly desirable; and example of such modeling is presented by Kalghati et al. [20]. A recent review of the vast history of engine knock is given by Chapman and Costanzo [21]. Based on genetic algorithm, a model for knock onset was formulated recently, considering multi-variable effects including pressure, temperature, EGR ratio and excess air ratio $(\mathrm{k})$ [22]. One dimensional simulation shows that knock occurrence and amplitude of pressure oscillations depend on the presence of negative temperature coefficient (NTC) [23]. While there are models for one dimensional engine cycle simulation, three-dimensional simulation on knock is also prevalent. A study reports the prediction of knock onset, pressure oscillation and 
knock intensity by coupling a reduced chemical kinetic reaction mechanism with 3D CFD code [24]. Theoretically, the auto ignition that occurs in a pre-ignition event is attributed to the reaction centers - "hot spots" caused by temperature gradient [ㄷ5]. This study reports that pre-ignition due to hot spots is not only due to end gas reaction, but also due to thermodynamic conditions that couples acoustic pressure waves with reaction front. The origin of hot spot through dissipation of turbulent kinetic energy was studied [26] and the parameter range in which detonation develops from secondary hot spot was identified in the study. The auto ignitive activation energy and temperature of hot spot was linked with detonation peninsula for normal auto ignition event, mild knock and super knock.

In the present pioneering study, we build a model of a pre-ignition cycle. The pre-ignition cycle is simulated systematically and results are analyzed to obtain a better understanding of the phenomenon. It is widely reported that engine oil from the liner, carbon deposits inside the engine and trapped end gas from previous cycle could be predominant reasons for pre-ignition in SI engines. In this paper, we are not interested in determining the source that triggers pre-ignition in engine, which is not completely understood; instead an insight of events are explored after pre-ignition. It can happen anywhere inside the combustion chamber and may or may not develop into a super knock event. The factors that determine the transition of pre-ignition to super knock are location of hot spots and timing at which hot spot induces pre-ignition. Therefore, we have performed this simulation study that investigates 1) the effect of hot spot location on preignition, 2) the effect of hot spot timing on pre-ignition. Hot spots were used to represent the pre-ignition source that evolves into a pre-ignition flame (PIF). The hot spots timings are -180 CAD (aTDC), -90 CAD (aTDC) and -30 CAD (aTDC). The locations of hot spots are at the center and two edges of the piston surfaces at opposite sides. The simulation study is performed using three dimensional computation code, CONVERGETM and the results of the analysis are presented.

\section{Computational Methodology}

Full cycle three-dimensional simulations were performed with CONVERGETM, a commercial code that couples flow turbulence, combustion chemistry with moving structures. The engine is the KAUST AVL SI engine with GDI injection. The mesh is generated during the run time in CONVERGE. A base grid of $4 \mathrm{~mm}$ is used in all directions with Adaptive Mesh Refinement (AMR) of level 5 which refines the cells locally to achieve a minimum cell size of $0.125 \mathrm{~mm}$ [Minimum cell size $=\mathrm{dx} / 2^{\text {(level) }}$ to capture the flame front. A constant cell refinement of level 5 is used during the spray injection to capture the entire spray event with higher resolution. CAD geometry developed for the study is shown in Figure 1 (a) with valves and Figure 1 (b) shows the mesh generated during the runtime in CONVERGE with AMR. Simulations were initially performed to match the experimental motoring cycle to match the peak pressure reached at TDC and to obtain the initial and boundary conditions for the pre-ignition simulations. The above said refinement level and base grid provided grid independent results (not shown).
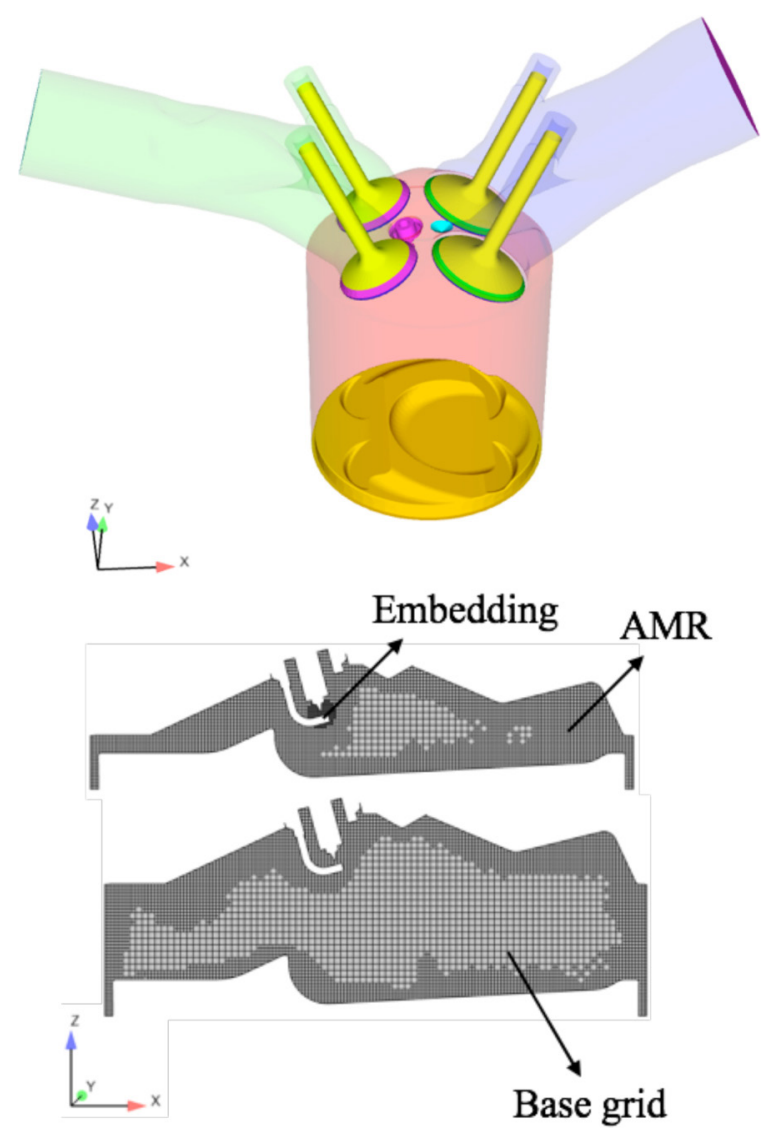

Figure 1. (a) AVL SI engine geometry developed for the pre-ignition simulations (top), (b) Grid generated for the study (bottom).

Reynolds averaged Navier-Stokes (RANS) was used to represent time averaged flow field. RNG k-epsilon model developed by Han and Reitz et al. [27] was to represent the in-cylinder turbulence. Heat loss to the cylinder walls was accounted using heat loss model developed by Han and Reitz et al. [28] . Finite volume method was used to discretize the computational domain with conservation of mass, momentum and energy represented by conservation equations which were explained in detail previously by Som et al. [려] . The valve profiles were incorporated to the code to reproduce the valve lift in the experiments. The spark plug was modeled using delta shape energy deposition model to represent the arc discharge and glow phase.

\section{Spray Modeling}

Kelvin-Helmholtz Rayleigh Taylor (KH-RT) spray breakup model $[\underline{30}, \underline{31}]$ was used model the gasoline direct injection (GDI) spray at an injection pressure of 135 bar during intake valve opening (IVO) event. The model assumes that liquid core is formed at exit of the nozzle and the core breaks down due to the instability arising over the surface of the liquid core providing larger droplets. These larger droplets from core are governed by the KH-RT breakup model, which calculates the wavelength and frequency over the droplet surface and determines whether to further break the droplet into smaller droplets. The evaporation of the droplet is governed by mass conservation and heat transfer equations. The models for collision of droplets by Post and Abraham et al. [32] and coalescence of droplets by O'rourke et al. [33] was used. Rosslin-Rammler size distribution was used to model the initial droplet size distribution and also it was assumed that the droplet remains spherical throughout its lifetime. Uniform thermal conductivity was assumed inside the droplet with effective liquid to 
gas diffusivity calculated on the fly with Newton- Raphson method. Liquid property database was incorporated to the code for the fuel used in the simulations. Detailed information of the entire model in this paragraph can be found in the CONVERGE manual [녀].

\section{Combustion Modeling}

The hotspot that leads to pre-ignition has a spherical patch region with Gaussian temperature profile of $2000 \mathrm{~K}$ to ensure that preignition is introduced inside the cylinder at desired crank angles. After some preliminary tests, it was found that a temperature of 2000 $\mathrm{K}$ and radius of $1 \mathrm{~mm}$ for the hotspot were suitable choices to develop the PIF. The value $2000 \mathrm{~K}$ and size of the hot spot is an ambiguous value and the results may be sensitive to these parameters, which are not discussed, in the present work. The hot spot is present at the edge of piston momentarily and is removed from the domain due to movement of piston towards the TDC. Experimentally, the source that induced the pre-ignition flame may be present throughout the cycle but in this study the source is removed during the run time, like it is said before that the focus will be on the events after the start of pre-ignition event. Methods to avoid pre-ignition are most interesting and are not part of this paper and is part of our research, but not reported in this work. The chemical kinetic mechanism developed by Liu et al. [35] is used to represent the iso-octane chemistry while the g-equation model coupled with a multi-zone model is used to solve the gas phase kinetics. The flame front progress is governed by g-equation model [36] through flame isosurface that differentiates the burnt and unburnt regions. These two regions are governed by multi-zone model developed by

Babajipoulous et al. [37], which can capture the auto-ignition (knock) inside the cylinder. Limitations of the combustion model are reported in literature $[\underline{36}, \underline{37}]$. A schematic representation of the modeling approach is shown in Figure 2. AMR with a refinement level of 5 was utilized in the flame front.

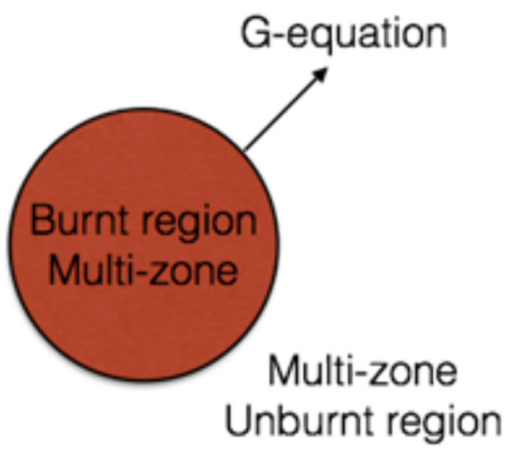

Figure 2. Schematic of combustion models used in simulations indicating the regions of application of multi-zone and G-equation models.

\section{Numerical Case Setup}

The specifications of the engine that is modeled in CONVERGE are shown in Table 1. The engine runs at a compression ratio of 9.5 and tested at low speed/full load conditions, wherein pre-ignition is prevalent. The engine cycle simulations were performed for operating conditions shown in Table 2. The results of normal combustion (NC) cycle are first analyzed for better understanding of the operation of engine in the above said operating conditions. To facilitate computational ease, iso-octane is selected for experiment. At the spark timing of -7 CAD (aTDC), the peak in-cylinder pressure for iso-octane is 50 bar. As the spark timing is advanced from $0 \mathrm{CAD}$ to
$-15 \mathrm{CAD}$, the in-cylinder pressure increases. These experimental results are used as the baseline data for comparing with simulation results obtained in the current study. The normal combustion (NC) cycles were first simulated, demonstrating the ability of the code to reproduce the experimental result and validate the computational approach. The chemical reaction mechanism for iso-octane is incorporated and the simulation is performed in CONVERGE. Figure $\underline{3}$ shows the comparison of experimental and simulated in-cylinder pressure. A good agreement between the simulation and experimental results give confidence of the model fidelity.

Table 1. KAUST's AVL engine specifications.

\begin{tabular}{|l|l|}
\hline Bore & $85 \mathrm{~mm}$ \\
\hline Stroke & $90 \mathrm{~mm}$ \\
\hline Connecting rod length & $138 \mathrm{~mm}$ \\
\hline Compression ratio & 9.5 \\
\hline Valves & 2 -intake and 2- exhaust valves \\
\hline Spark plug energy & $40 \mathrm{~mJ}$ (L shaped energy profile) \\
\hline Spark time & -15 CAD, -7 CAD \& 0 CAD \\
\hline
\end{tabular}

Table 2. Operating conditions for the present study

\begin{tabular}{|l|l|}
\hline RPM & 1200 \\
\hline Intake temperature & $300 \mathrm{~K}$ \\
\hline Intake pressure & 1 bar \\
\hline Lambda & 1 \\
\hline Fuel & iso-octane \\
\hline
\end{tabular}

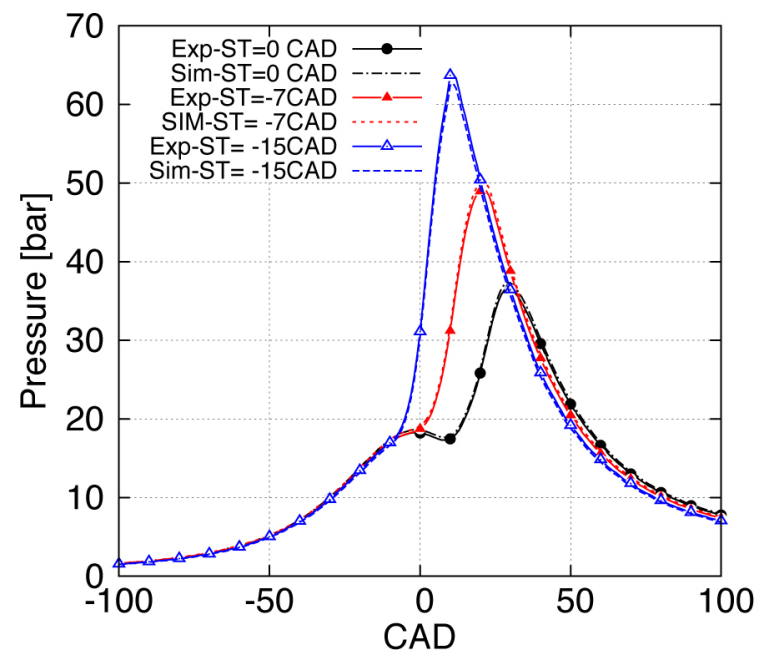

Figure 3. In-cylinder pressure comparisons between experiments and simulations results at various spark timing.

\section{Knock Methodology}

To increase the temporal resolution of the simulations and the ability of the code to capture the pressure oscillations inside the cylinder due to knock, the maximum allowed time step was further restricted from -30 CAD onwards. The maximum CFL Mach number was set to 1.5 from -30 CAD since smaller values of CFL number increases the ability of the code to capture the pressure oscillations inside the cylinder as reported by Park et al. [38]. It has been demonstrated by Park et al. that location of formation of in-cylinder $\mathrm{H}_{2} \mathrm{O}_{2}$ greater than or equal to a value of $4 \mathrm{e}-04 \mathrm{~kg} / \mathrm{kg}$ indicates the location of knock inside the cylinder by utilizing visio knock sensor. Figure A1 shows 
the simulated flame progress inside the cylinder at multiple crank angles after spark. The production of $\mathrm{H}_{2} \mathrm{O}_{2}$ inside the cylinder is also shown to use the species as an indicator of the region inside the cylinder that is more favorable for auto-ignition. The $\mathrm{H}_{2} \mathrm{O}_{2}$ species value greater than or equal to $4 \mathrm{e}-04 \mathrm{~kg} / \mathrm{kg}$ will be used as an indicator to indicate the regions that are more prone to knock and will be called "threshold limit" throughout this study. This methodology is adopted in the current simulation study because pre-ignition is a stochastic event and numerical method used to model pre-ignition is RANS, which represent time averaged solution. The proper method to model pre-ignition is by utilizing large eddy simulation (LES), which can predict the cycle-to-cycle variations and capture the knock phenomenon. Since LES is computationally expensive, RANS is used to understand the events following the pre-ignition event.

\section{Case Study on Pre-Ignition by Hotspots}

In the present study, pre-ignition is induced by creating hot spot in the piston surface. Hot spot is placed either at the center or edge of the piston, at different crank angles. Based on this, the following two objectives are studied in the present simulation study 1) Effect of hot spot timing on pre-ignition (CASE A, CASE B and CASE E), 2) Effect of location of hot spot on pre-ignition (CASE D, CASE E and CASE F). Figure 4 illustrates the cases with hotspots at various locations and timings, which are studied in the present study. The flame propagation from each hot spot is examined and the temperature distribution of the pre-ignition event is presented. Utilizing the mass profiles and mass fraction of $\mathrm{H}_{2} \mathrm{O}_{2}$ and $\mathrm{CH}_{2} \mathrm{O}$, knock and knock prone regions which favors auto-ignition are investigated. The pressure oscillations from the in-cylinder pressure curve, rate of heat release and un-burnt gas temperature are also presented for different cases.

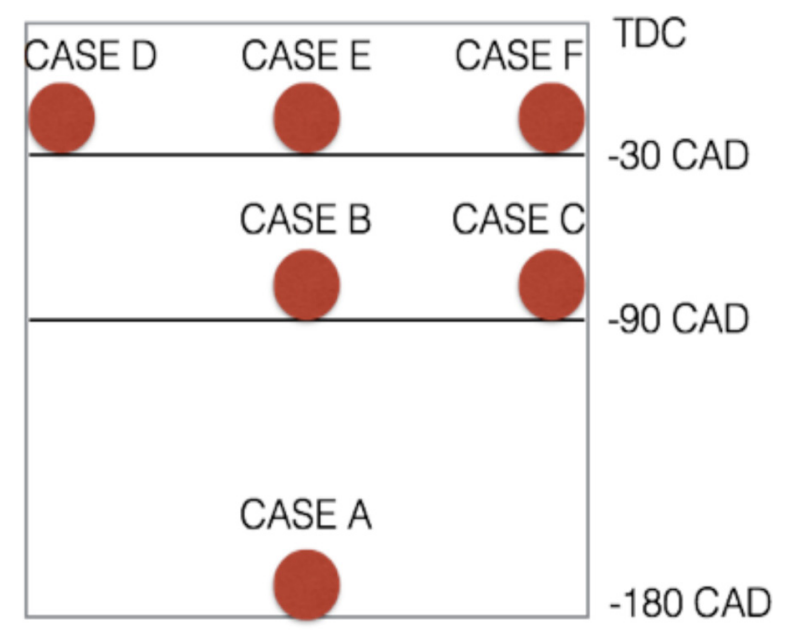

Figure 4. Representation of the location and timing of the hotspot at various positions (edges or center) inside the cylinder

\section{Results and Discussion}

\section{Effect of Hot Spot Timing on Pre-Ignition (CASE A, CASE $B$ and CASE $E$}

Initially, the hot spot was placed at the center of the piston at a timing of -180 CAD (CASE A) to induce a pre-ignition event and the effect is analyzed. Figure 5(a) shows the in-cylinder pressure trace and rate of heat release obtained for CASE A. A change in slope is observed in the pressure trace at around $-70 \mathrm{CAD}$ due to combustion. All the fuel is consumed before the piston reaches TDC and burnt gas was compressed by the piston. The rate of heat release is zero around -70 $\mathrm{CAD}$, implying end of combustion (EOC) and the second heat release is due to spark discharge. From Figure 5(b), it can be observed that maximum pressure is similar to the mean volume averaged pressure and no oscillation in pressure trace is seen. It shows that pre-ignition when induced at early crank angles will not lead to knock or super-knock. This is because most of the fuel is burnt during the compression stroke itself. The unburnt gas temperature is around 600 $\mathrm{K}$ at EOC, showing that there is no knock.
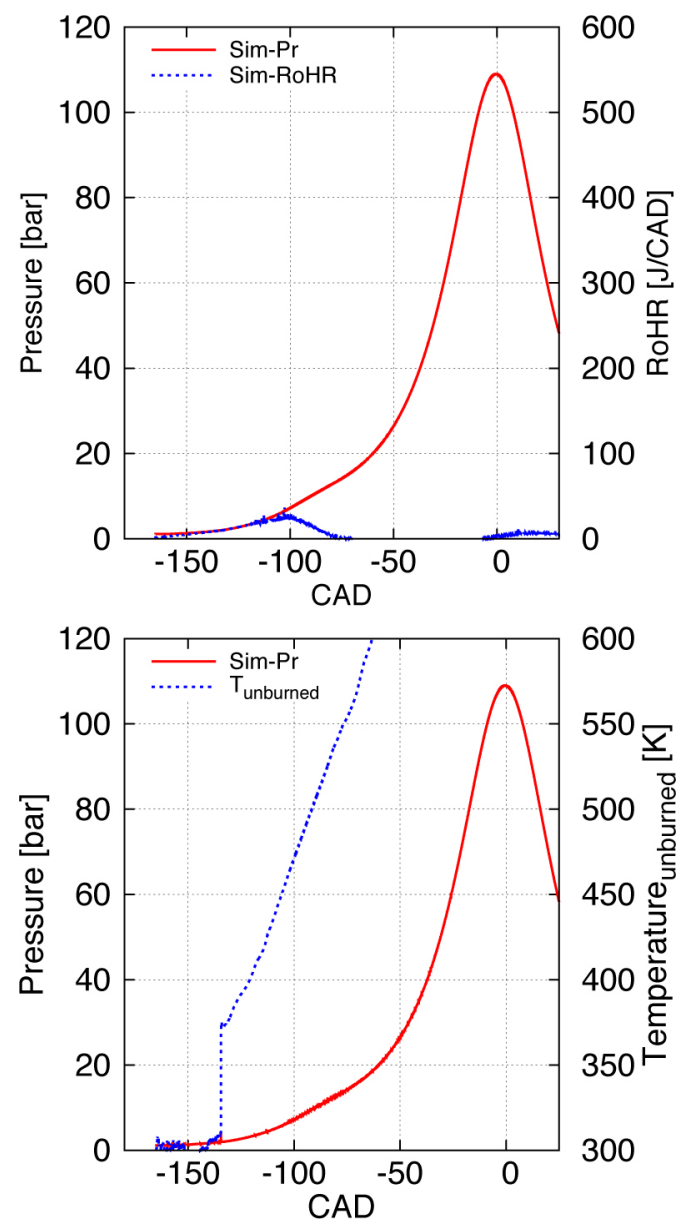

Figure 5. (a) In-cylinder mean pressure and heat release rate(top), (b) peak pressure and endgas temperature for CASE A (bottom).

Figure 6 shows the pre-ignition location and PIF evolution inside the cylinder at various crank angles for CASE A. The PIF progressed as a smooth flame front without any sudden acceleration and no autoignition sites inside the cylinder is observed. The fuel mass variation during the cycle, and $\mathrm{CH}_{2} \mathrm{O}$ and $\mathrm{H}_{2} \mathrm{O}_{2}$ mass profiles are shown in Figure 7. It is clear form the figure that all the fuel is consumed at around -70 CAD. Low values of $\mathrm{H}_{2} \mathrm{O}_{2}$ species indicate that no region inside the cylinder is prone to knock due to the absence of low temperature reactivity. The temperature and $\mathrm{H}_{2} \mathrm{O}_{2}$ species formation at various crank angles are shown in Figure A2. The location of the hotspot that initiates pre-ignition and PIF are shown in two different views (bottom view and iso-metric view) to obtain a better understanding of the distributions inside the cylinder. The value of $\mathrm{H}_{2} \mathrm{O}_{2}$ mass fraction remains below the preset threshold limit, which indicates that there was no auto-ignition or a region inside the cylinder that exhibits reactive mixture. It could be noted that $\mathrm{H}_{2} \mathrm{O}_{2}$ is 
highly reactive in the NTC (negative temperature co-efficient) region, which is similar to the temperature range at which the knock is triggered inside the cylinder [39].

CAD -177

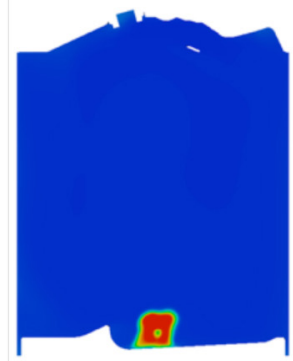

CAD -143

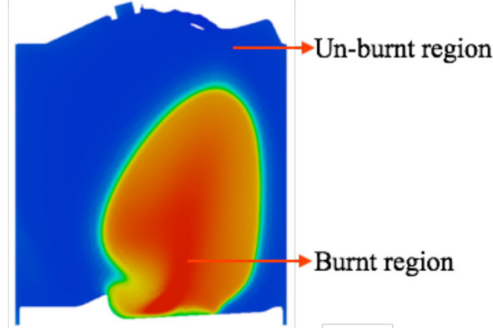

CAD -87

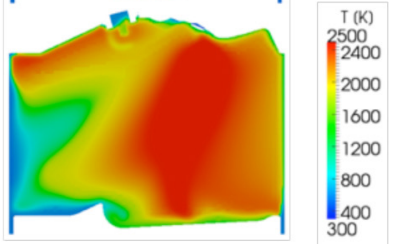

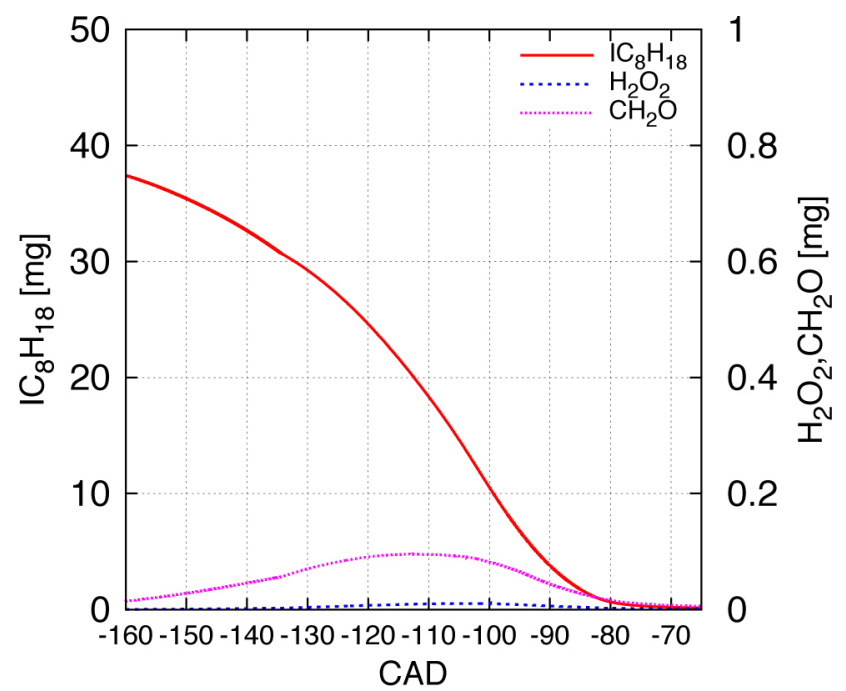

Figure 7. Time history of fuel $\left(\mathrm{IC}_{8} \mathrm{H}_{18}\right)$ mass with $\mathrm{CH}_{2} \mathrm{O}$ and $\mathrm{H}_{2} \mathrm{O}_{2}$ formation inside the cylinder for CASE A.

Figure 6. Y-slice showing the location of the pre-ignition and flame propagation at various crank angles for CASE A.
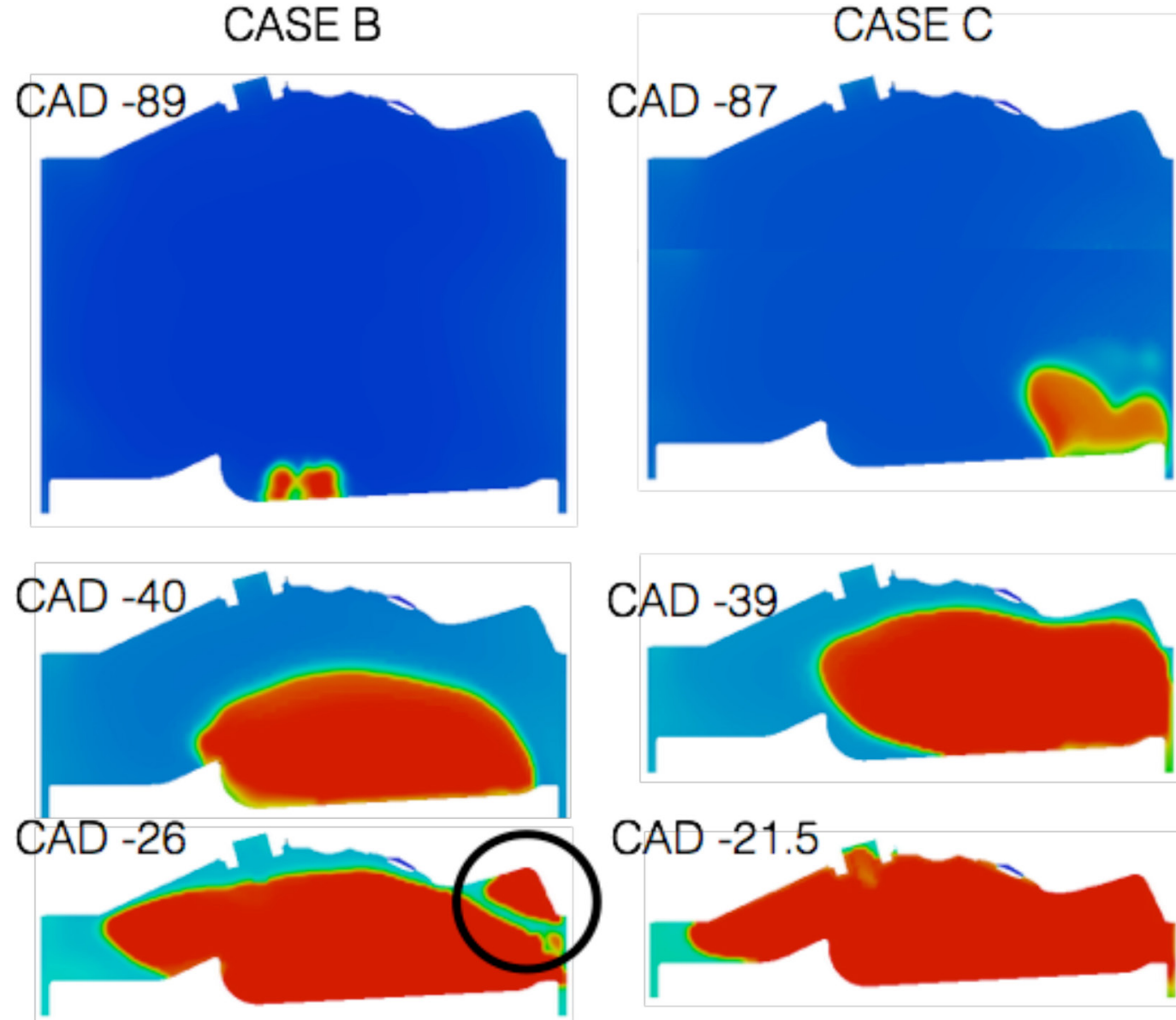

\section{CAD -21.5}

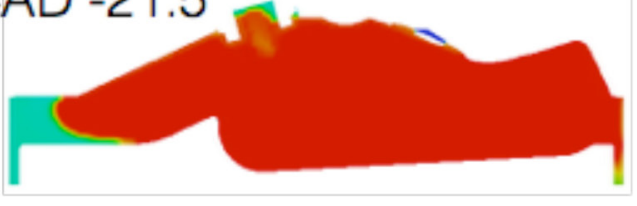



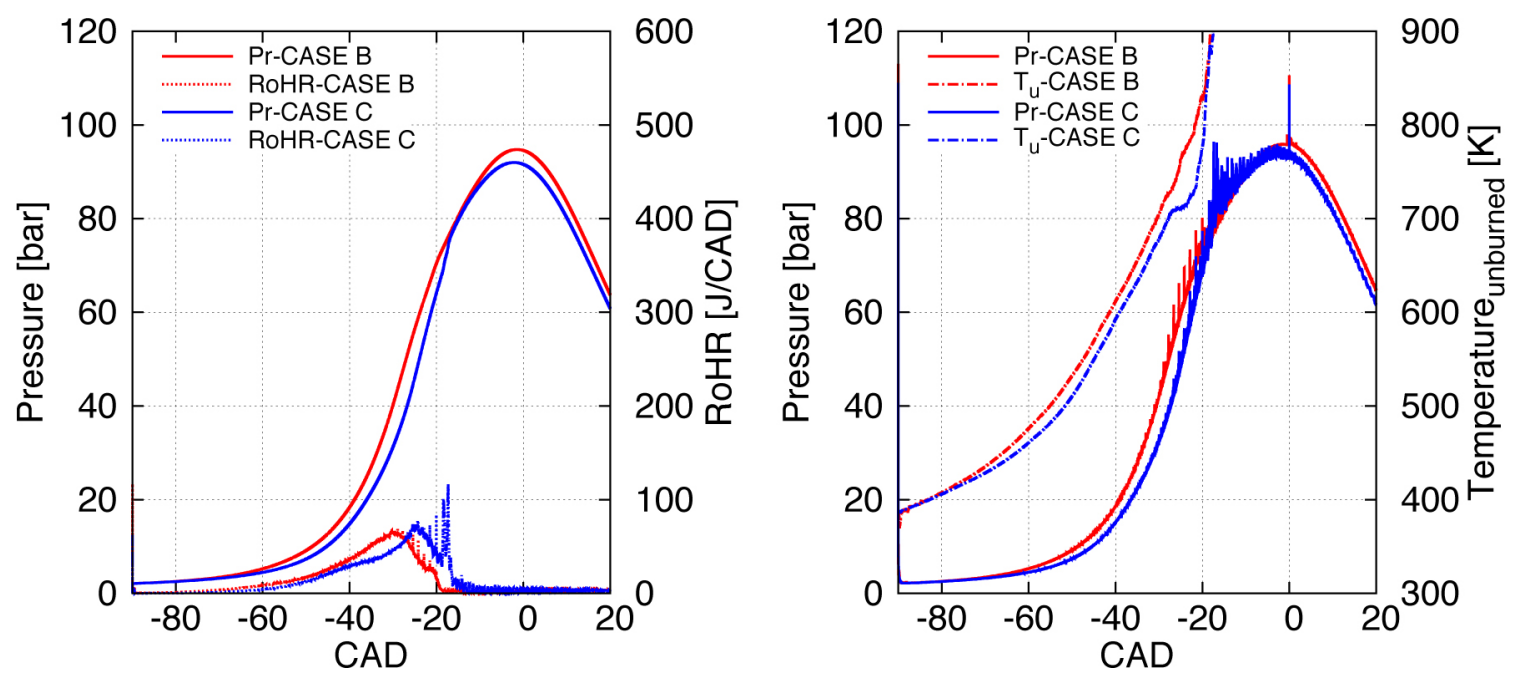

Figure 9. (a) In-cylinder mean pressure and heat release rate (RoHR) (left), (b) Peak pressure and end gas temperature (right) for CASE B and CASE C.

At -90 CAD, the hot spot is at the center of the piston surface for CASE B and near the cylinder wall over the piston surface for CASE C. The flame front is initiated from the piston surface, which shows a smooth propagation, until the piston reaches TDC for both the cases. The Y-slice comparison reveals the location of pre-ignition and the PIF initiated at the surface of the cylinder. Auto-ignited region for CASE B near the cylinder head is marked and shown in Figure 8 . The auto-ignition (knock) of the mixture is due to the increase in temperature of the unburnt mixture, caused by compression of the mixture by the piston and flame front.

The auto-ignited spot can couple with pressure waves and lead to high pressures as reported by Robert et.al. [40]. Formation of $\mathrm{H}_{2} \mathrm{O}_{2}$ is observed at the flame front, which is a typical characteristics of hydrocarbon flames but the mass fraction of $\mathrm{H}_{2} \mathrm{O}_{2}$ reveals that most of the end gas region has started reacting and undergoes decomposition phase, leading to knock as shown in Figure A3.

The in-cylinder mean volume averaged pressure is higher during the compression stroke, as shown in Figure 9(a). Investigation of maximum pressure indicates a sharp rise in pressure before the piston reaches TDC, as illustrated in Figure 9(b). The heat release rate shows that the fuel is consumed before the piston reaches TDC. This implies that at later crank angles, the piston compresses only the burnt end gas (as in CASE A). The pressure curve exhibits a change in slope at the crank angle of -20 CAD, which is another indication of compression of the burnt gas inside the cylinder. Peak pressure shows some oscillations, which indicate knock near EOC but also resembles the mean averaged pressure. The end gas temperature history shown in Figure 9(b) indicates a temperature range of 600-800 K near EOC.

The study on effect of hot spot timing on pre-ignition clearly identifies that a hot spot timing at -180 CAD doesn't lead to knock. This is attributed to the consumption of fuel during the compression stroke. On the other hand, hotspot at -90 CAD showed signs of auto-ignition in the end gas. Though the pressure oscillations are not severe at $-90 \mathrm{CAD}$, it is evident that pre-ignition could lead to knock, heavy knock or super-knock for hot spot timing after -90 CAD. Investigation of pressure from CASE E clearly exhibits super-knock, which is discussed in detail later.

\section{Effect of Location of Hot Spot on Pre-Ignition (CASE D, CASE E and CASE F}

The hotspot is placed at the center (CASE E) and two edges of the piston surfaces at opposite sides (CASE D and CASE F). The comparison is made at the same hot spot timing of -30 CAD so that the effect of location of hot spot on pre-ignition can be comprehended. The location of hotspot and the flame propagation inside the cylinder is shown in Figure 10 at various crank angles. The knock locations are marked in Figure 10; showing that flame propagation in CASE F is faster when compared to CASE D. The difference between CASE D and CASE F is due to the shape of the piston, which is able to contain the flame for few CAD. From these observations, it is clear that the geometry of the engine is also an important factor for the pre-ignition cycle to result in super-knock. Thus, besides the location and timing of hotspot, the engine geometry also proves crucial during a pre-ignition event. In addition, the local turbulence and mixture conditions also play a major role.

Flame acceleration is observed in CASE D, CASE E and CASE F as the flame front approaches the end-wall. Strong formation of $\mathrm{H}_{2} \mathrm{O}_{2}$ is detected in the end gas region, indicating the reactivity of end gas for all the three cases. Thus, auto-ignition of end gas is observed for all three cases, which is understood from the presence of $\mathrm{H}_{2} \mathrm{O}_{2}$ fractions in Figure 11. It is noteworthy to point out that $\mathrm{H}_{2} \mathrm{O}_{2}$ fractions are seen in the flame front for CASE D and CASE F. Since the hot spot is in the center for CASE E, $\mathrm{H}_{2} \mathrm{O}_{2}$ mass fraction distribute widely on both sides of combustion chamber which indicates that those regions are more prone to auto-ignition.

For both CASE E and CASE F, the mean in-cylinder pressure is around 90 bar whereas, the maximum pressure is higher than 250 bar (Figure 12). This is an indication that these pre-ignition cycles may lead to a super knock event. The rate of heat release indicates that all fuel is consumed near TDC for CASE E and CASE F whereas fuel is available until $26 \mathrm{CAD}$ for CASE D. The heat release rate curve for CASE E is sharper and shorter, which indicates that a large amount of fuel is consumed in a very small period of time. Based on these observations, it can be said that the probability of having a superknock cycle is higher when pre-ignition occurs at very late crank angles, burning a large amount of fuel in a very short time. It can also be noted that PIF that was initiated at side of the piston (CASE F) exhibits higher maximum pressure when compared with other cases. 
CASE D
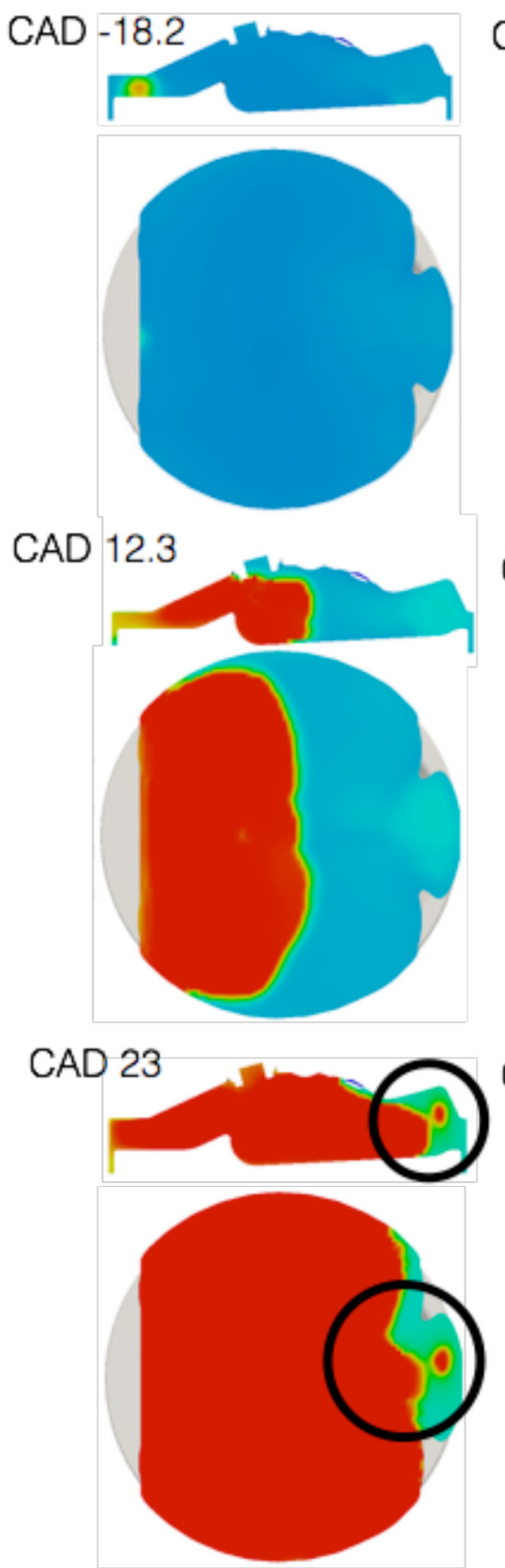

CASE E

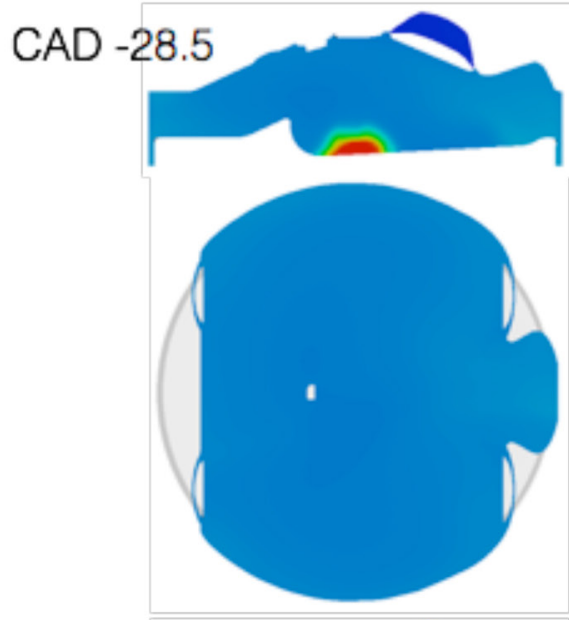

CAD
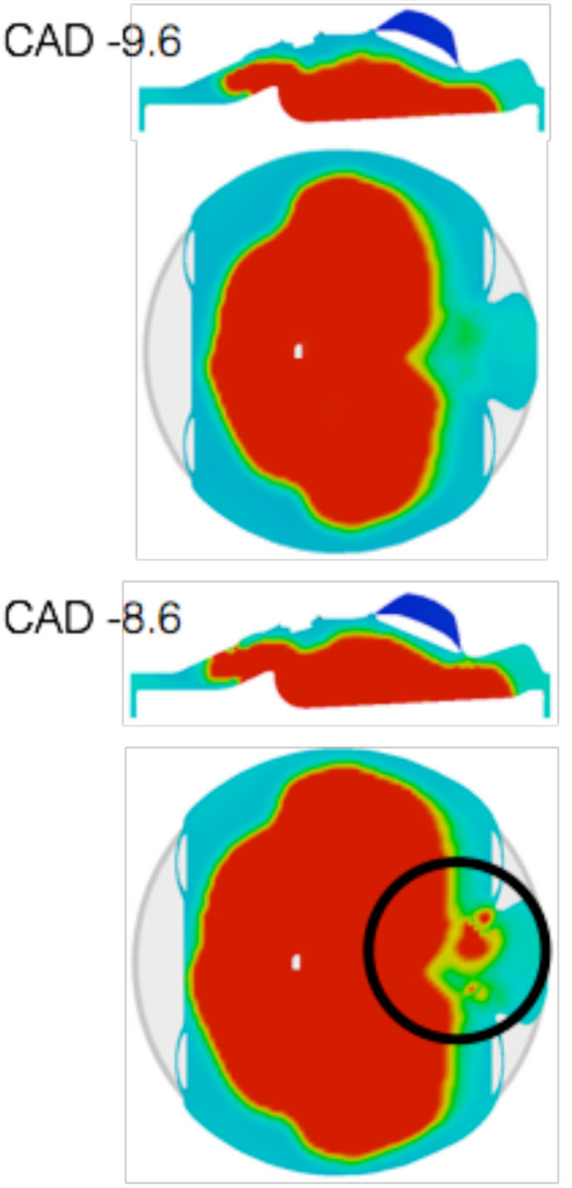

CASE F

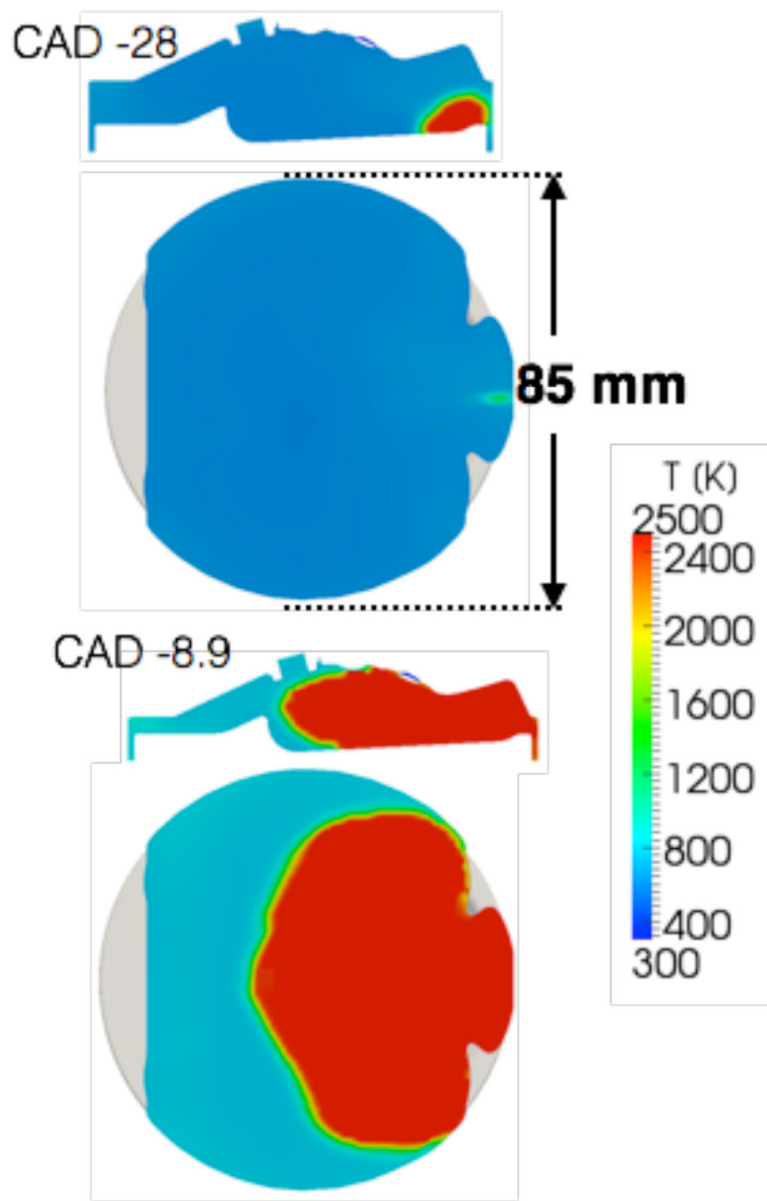

CAD -4.1

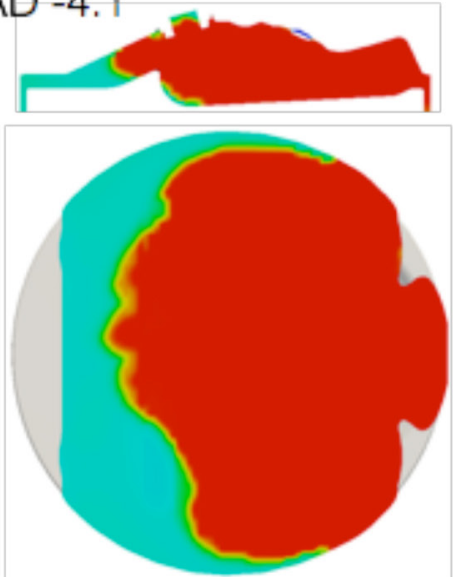

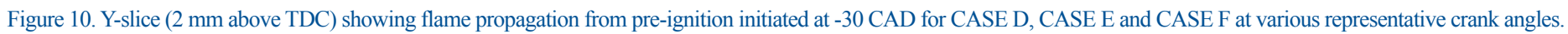

The variation of unburnt gas temperature for CASE D, CASE E and CASE $\mathrm{F}$ is plotted with respect to crank angle and shown in Figure 13. When the temperature of the unburnt gas is higher, fuel is consumed faster and this gives an indication of a pre-ignition cycle leading to super knock. It can be inferred that CASE E and CASE F have the highest unburnt gas temperature when compared to other cases. Unburnt gas at a high temperature near to TDC can cause bulk ignition or auto-ignition (thermal explosion) of the mixture to increase the in-cylinder pressure oscillations.
At late hot spot timing of -30 CAD, auto-ignition of end gas is evident irrespective of the location of the hot spot. Abnormal combustion event (super knock) is noticed for CASE E and CASE F, while CASE D is a pre-ignition event with mild knock. Since the combustion occurred late after TDC for CASE D, the event is not disastrous. This is attributed to the geometry of the combustion chamber, which forbids the transition of pre-ignition event to super knock. For the current piston geometry the location of hot spot in CASE E and CASE F is vulnerable in that it lead to super knock. 
Temperature

CASE D

CAD 23

\section{(1)}

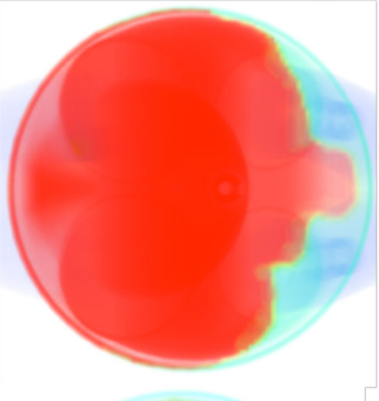

CASE E

CAD -6.8

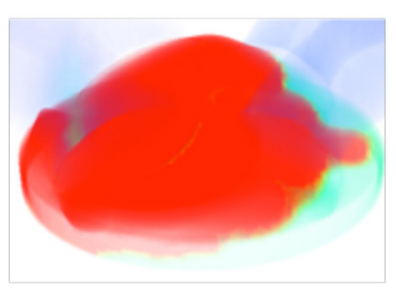

\section{Mass fraction}

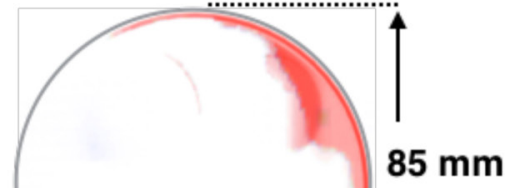

CASE F CAD -5.7

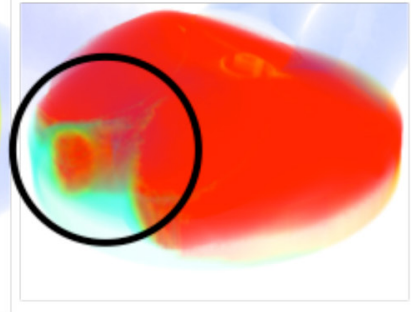

Isometric view
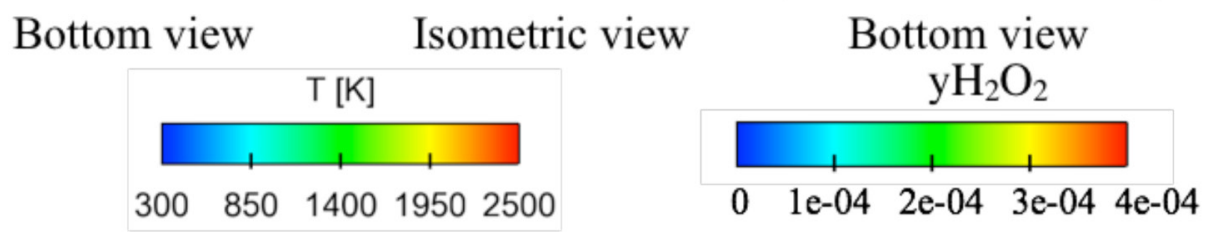

Figure 11. Volume rendered temperature and $\mathrm{H}_{2} \mathrm{O}_{2}$ species formation at various crank angles for CASE D, CASE E and CASE F.
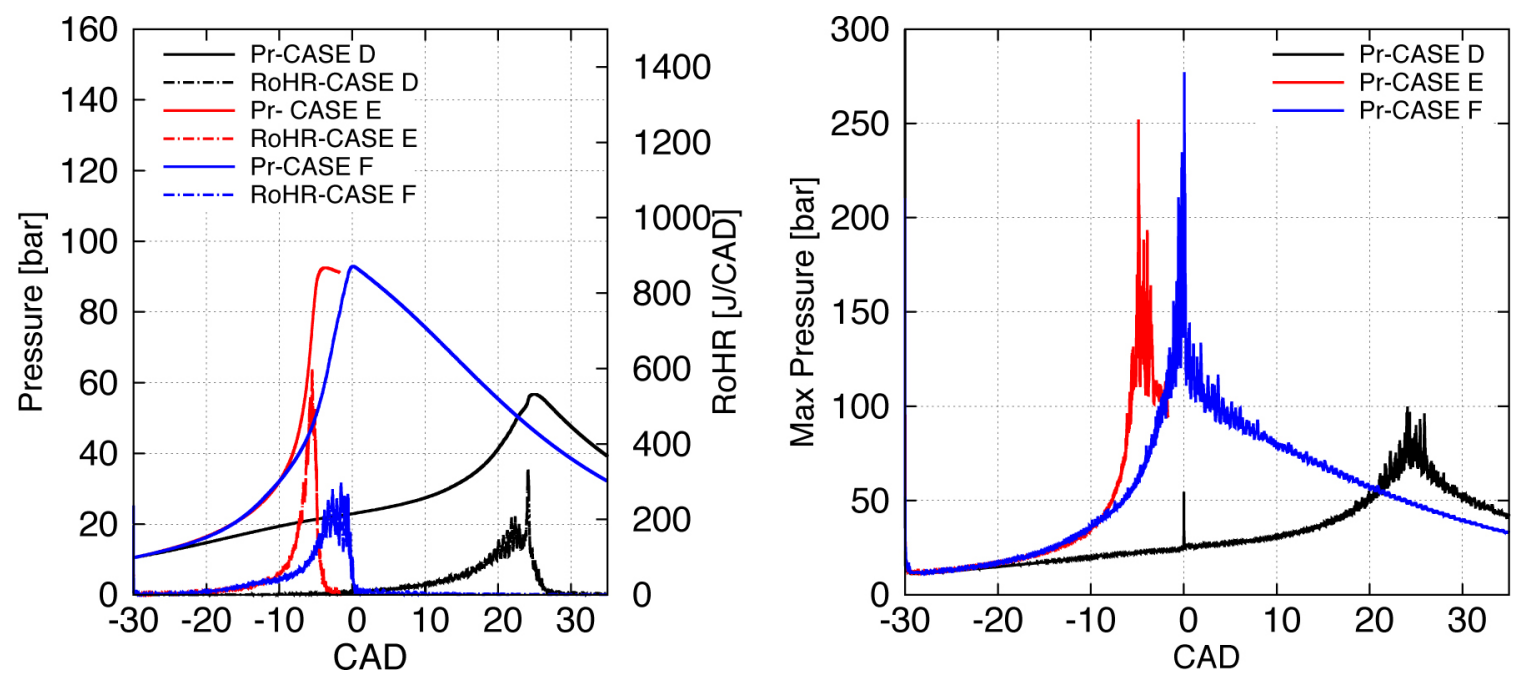

Figure 12. (a) In-cylinder volume averaged mean pressure and heat release rate (RoHR) (left), (b) maximum pressure (right) for CASE D, CASE E and CASE F 


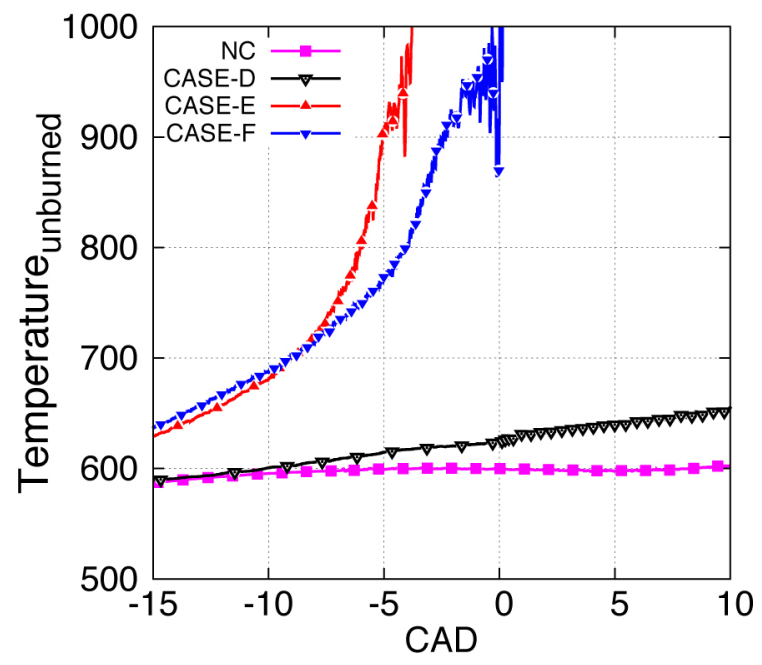

Figure 13. End gas temperatures for various cases, Note NC-Normal Combustion.

\section{Conclusions}

Previous studies show that pre-ignition is induced by hotspot anywhere inside the combustion chamber. However, not all preignition event leads to super knock. Therefore, the location and timing of hotspot inside the combustion chamber is critical in determining the possibility of a pre-ignition event leading to super knock. To ascertain this, a pre-ignition cycle was studied using a 3D CFD software, CONVERGE, in a SI engine by initiating a preignition flame at various location and timings. Pre-ignition model was developed utilizing economical RANS turbulence. In the present study, the hot spot timings are chosen at -180 CAD, -90 CAD and -30 CAD. Further, the locations of the hot spots are in the center and two edges of the piston surfaces at opposite sides. A good agreement between the experimental data and simulation results is obtained for normal combustion cycles, validating the computational approach and sub models used in the simulations. The effect of hot spot timing on pre-ignition identifies that pre-ignition could lead to super knock at late hot spot timing. The hot spot placed at the early timing of -180 CAD shows that all the fuel is consumed before the piston reaches TDC. When considering the location of hot spot, geometry of the combustion chamber is important in ascertaining super knock cycle during a pre-ignition event. In the hot spots located at edge of the piston surface one lead to super knock (CASE F), while the other showed only mild knock (CASE D). Thus, it can be concluded that the pre-ignition event leading to super knock is possible for late hot spot timing irrespective of hot spot locations. The effect of hot spot location on pre-ignition event leading to super knock depends on engine geometry.

\section{References}

1. Vallinayagam, R., Vedharaj, S., Naser, N., Roberts, W. L., Dibble, R. W., Sarathy, S. M., "Terpineol as a novel octane booster for extending the knock limit of gasoline," Fuel. 187, 9-15, 2016, doi:10.1016/j.fuel.2016.09.034.

2. Lecointe, B. and Monnier, G., "Downsizing a Gasoline Engine Using Turbocharging with Direct Injection," SAE Technical Paper 2003-01-0542, 2003, doi:10.4271/2003-01-0542.
3. Ettefagh, M., Sadeghi, M., Pirouzpanah, V., Tash, H. A., "Knock detection in spark ignition engines by vibration analysis of cylinder block: A parametric modeling approach," Mech. Systems Signal Processing, 22(6), 1495-1514, 2008.

4. Grandin, B. and Denbratt, I., "The Effect of Knock on Heat Transfer in SI Engines," SAE Technical Paper 2002-01-0238, 2002, doi: 10.4271/2002-01-0238.

5. Harned, J. L., "Borderline spark knock detector," Google Patents, 1977.

6. Mittal, V., Revier, B., and Heywood, J., "Phenomena that Determine Knock Onset in Spark-Ignition Engines," SAE Technical Paper 2007-01-0007, 2007, doi:10.4271/2007-01-0007.

7. Zhen, X., Wang, Y., Xu, S., Zhu, Y., Tao, C., Xu, T., Song, M., "The engine knock analysis-An overview," Applied Energy, 92, 628-636, 2012, doi:10.1016/j.apenergy.2011.11.079.

8. Pan, J., Shu, G., Wei, H., "Research on in-cylinder pressure oscillation characteristic during knocking combustion in spark-ignition engine," Fuel, 120, 150-7, 2014, doi:10.1016/j. fuel.2013.11.054.

9. Peyton Jones, J., Muske, K., Frey, J., and Scholl, D., "A Stochastic Knock Control Algorithm," SAE Technical Paper 2009-01-1017, 2009, doi:10.4271/2009-01-1017.

10. Luo, W., Chen, B., Naber, J., and Glugla, C., "Stochastic Knock Detection, Control, Software Integration, and Evaluation on a V6 Spark-Ignition Engine under Steady-State Operation," SAE Technical Paper 2014-01-1358, 2014, doi:10.4271/2014-01-1358.

11. Chen, Y. and Raine, R., "Engine Knock in an SI Engine with Hydrogen Supplementation under Stoichiometric and Lean Conditions," SAE Int. J. Engines 7(2):595-605, 2014, doi: 10.4271/2014-01-1220.

12. Ohashi, Y., Fukui, W., Tanabe, F., and Ueda, A., "The Application of Ionic Current Detection System for the Combustion Limit Control," SAE Technical Paper 980171, 1998, doi:10.4271/980171.

13. Ohashi, Y., Koiwa, M., Okamura, K., and Ueda, A., "The Application of Ionic Current Detection System for the Combustion Condition Control," SAE Technical Paper 1999-010550, 1999, doi:10.4271/1999-01-0550.

14. Alkidas AC., "Combustion advancements in gasoline engines," Energy Conversion and Management, 48(11), 2751-61, 2007, doi:10.1016/j.enconman.2007.07.027.

15. Li, T., Nishida, K., Zhang, Y., Hiroyasu, H., "Effect of split injection on stratified charge formation of direct injection spark ignition engines," Int. J Eng Res, 8(2), 205-19, 2007.

16. Alger, T., Gingrich, J., Roberts, C., Mangold, B., "Cooled exhaust-gas recirculation for fuel economy and emissions improvement in gasoline engines," Int. J Eng Res, 12(3), 252-64, 2011.

17. Lauer, T., Heiss, M., Bobicic, N., Holly, W. , "A Comprehensive Simulation Approach to Irregular Combustion," SAE Technical Paper 2014-01-1214, 2014, doi:10.4271/2014-01-1214.

18. Dahnz, C., Han, K., Spicher, U., Magar, M. , "Investigations on Pre-Ignition in Highly Supercharged SI Engines," SAE Int. J. Engines 3(1):214-224, 2010, doi:10.4271/2010-01-0355. 
19. Gupta, A., Shao, H., Remias, J., Roos, J. , "Relative Impact of Chemical and Physical Properties of the Oil-Fuel Droplet on Pre-Ignition and Super-Knock in Turbocharged Gasoline Engines," SAE Technical Paper, 2016-01-2278, 2016, doi: 10.4271/2016-01-2278.

20. Kalghatgi, G., Morganti, K., Algunaibet, I., Sarathy, M. , "Knock Prediction Using a Simple Model for Ignition Delay," SAE Technical Paper 2016-01-0702, 2016, doi:10.4271/2016-01-0702.

21. Chapman, E. and Costanzo, V., "A Literature Review of Abnormal Ignition by Fuel and Lubricant Derivatives," SAE Int. J. Engines 9(1):107-142, 2016, doi:10.4271/2015-01-1869.

22. Chen, L., Li, T., Yin, T., Zheng, B., "A predictive model for knock onset in spark-ignition engines with cooled EGR," Energy Conversion and Management, 87, 946-55, 2014, doi:10.1016/j.enconman.2014.08.002.

23. Terashima, H., Koshi, M., "Mechanisms of strong pressure wave generation in end-gas autoignition during knocking combustion," Combust Flame, 162(5), 1944-56, 2015, doi:10.1016/j.combustflame.2014.12.013.

24. Shu, G., Pan, J., Wei, H., "Analysis of onset and severity of knock in SI engine based on in-cylinder pressure oscillations," Applied Thermal Engineering, 51(1), 1297-306, 2013.

25. Rudloff, J., Zaccardi, J. M., Richard, S., Anderlohr, J., "Analysis of pre-ignition in highly charged SI engines: Emphasis on the autoignition mode," Proci of the Comb Inst, " 34, 2959-67, 2013.

26. Bates, L., Bradley, D., Paczko, G., Peters, N., "Engine hot spots: Modes of auto-ignition and reaction propagation," Combust Flame. 166, 80-5, 2016.

27. Han, Z., Reitz, R. D., "Turbulence modeling of internal combustion engines using RNG $\kappa-\varepsilon$ models, Combust. sci. and tech, " 106(4-6), 267-295, 1995, doi: $10.1080 / 00102209508907782$.

28. Han, Z., Reitz, R. D., "A temperature wall function formulation for variable-density turbulent flows with application to engine convective heat transfer modeling," Int. J. heat mass transfer, " 40(3), 613-625, 1997, doi:10.1016/0017-9310(96)00117-2.

29. Som, S., Aggarwal, S.K., "Effects of primary breakup modeling on spray and combustion characteristics of compression ignition engines, Combust Flame, " 157(6), 1179-1193, 2010, doi:10.1016/j.combustflame.2010.02.018.

30. Reitz, R. and Diwakar, R., "Effect of Drop Breakup on Fuel Sprays," SAE Technical Paper 860469, 1986, doi: $10.4271 / 860469$.

31. Reitz, R. and Diwakar, R., "Structure of High-Pressure Fuel Sprays," SAE Technical Paper $\underline{870598}, 1987$, doi: $10.4271 / 870598$.

32. Post, S.L., Abraham, J., "Modeling the outcome of drop-drop collisions in Diesel sprays. Int. J. of Multiphase Flow, " 28, 997-1019, 2002.
33. O'Rourke, P. and Amsden, A., "The Tab Method for Numerical Calculation of Spray Droplet Breakup," SAE Technical Paper 872089, 1987, doi: 10.4271/872089.

34. Richards, K., Senecal, P., Pomraning, E., CONVERGE 2.2.0 Theory Manual, Convergent Science Inc., Madison, WI, 2013.

35. Liu, Y.D., Jia, M., Xie, M.Z., Pang, B., "Development of a New Skeletal Chemical Kinetic Model of Toluene Reference Fuel With Application to Gasoline Surrogate Fuels for Computational Fluid Dynamics Engine Simulation," Energy Fuels, 27(8), 4899-4909, 2017, doi:10.1021/ef4009955.

36. Peters, N., "Turbulent combustion,"Cambridge university press, 2000.

37. Babajimopoulos, A., Assanis, D., Flowers, D., Aceves, S., Hessel R.P., "A fully coupled computational fluid dynamics and multi-zone model with detailed chemical kinetics for the simulation of premixed charge compression ignition engines," Int. J Eng Res. 6(5), 497-512, 2005, doi: 10.1243/146808705X30503.

38. Park, S. and Furukawa, T., "Validation of Turbulent Combustion and Knocking Simulation in Spark-Ignition Engines Using Reduced Chemical Kinetics," SAE Technical Paper 2015-010750, 2015, doi: 10.4271/2015-01-0750.

39. Sarathy, S. M., Kukkadapu, G., Mehl, M., Wang, W., Javed, T., Park, S., Oehlschlaeger, M.A., Farooq, A., Pitz, W.J., Sung, C.J., "Ignition of alkane-rich FACE gasoline fuels and their surrogate mixtures," Proci of the Comb Inst, 35(1), 249-257, 2015, doi:10.1016/j.proci.2014.05.122.

40. Robert, A., Richard, S., Colin, O., Poinsot, T., "LES study of deflagration to detonation mechanisms in a downsized spark ignition engine," Combust Flame, 162(7), 2788-2807, 2015, doi: 10.1016/j.combustflame.2015.04.010.

\section{Contact information}

Mr. Mohammed Jaasim Mubarak Ali

PhD Student

Clean Combustion Research Center (CCRC)

King Abdullah Univeristy of Science and Technology (KAUST)

Thuwal, Saudi Arabia

mohammedjaasim.mubarakali@kaust.edu.sa

Phone no- +966569060 779

\section{Acknowledgements}

This work was sponsored by the Saudi Aramco under the FUELCOM II program and by King Abdullah University of Science and Technology. The computational simulations utilized the clusters at KAUST Supercomputing Laboratory and IT Research Computing. 


\section{APPENDIX}

\section{APPENDIX-A}

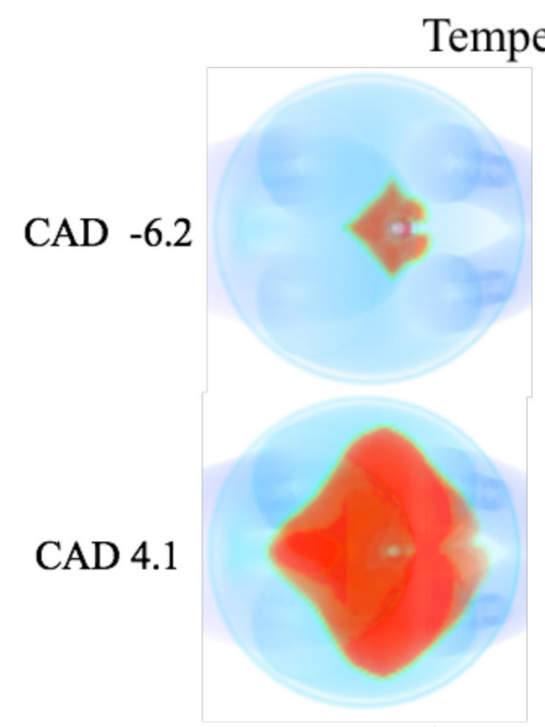

\section{Bottom view}

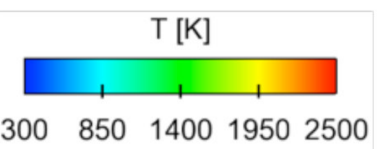

\section{Mass fraction}

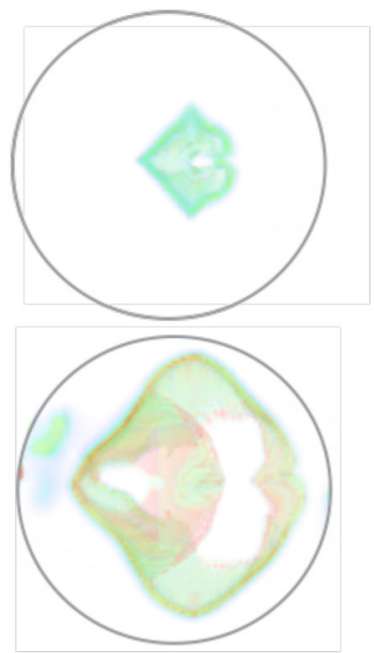

Bottom view

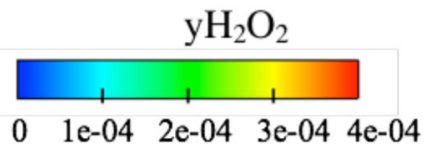

Figure A1. Volume rendered flame propagation and $\mathrm{H}_{2} \mathrm{O}_{2}$ mass fraction inside the cylinder at various crank angles for spark timing of -7 CAD.

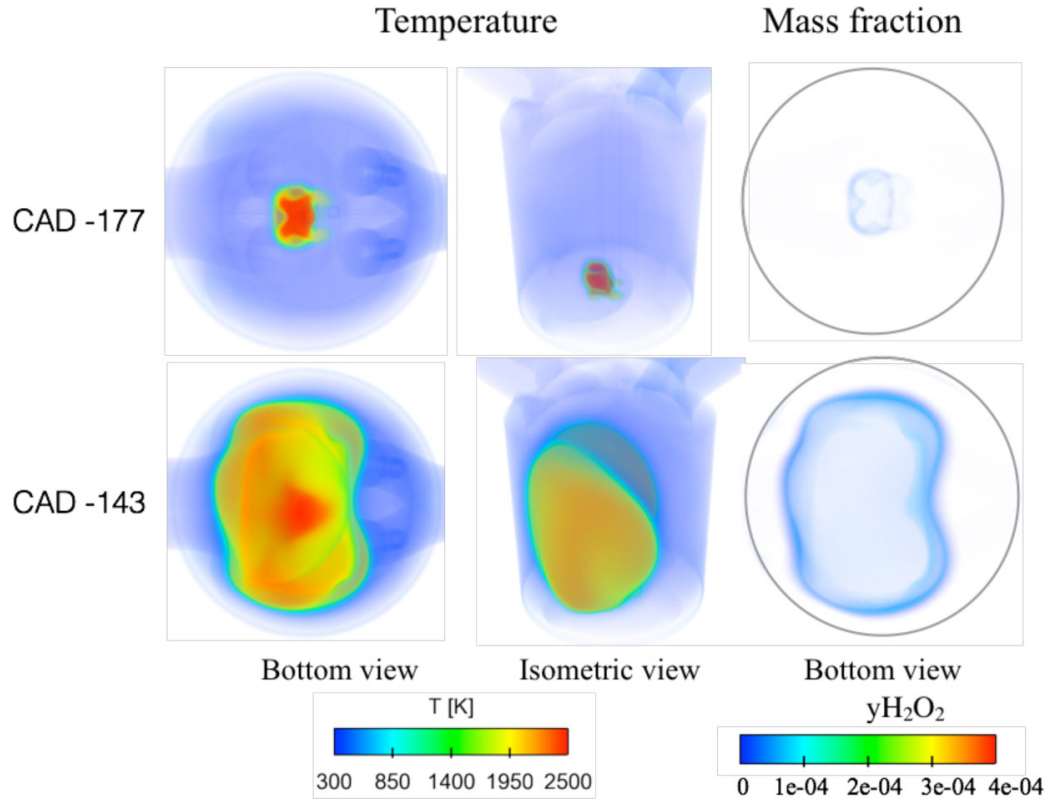

Figure A2. Volume rendered temperature and $\mathrm{H}_{2} \mathrm{O}_{2}$ mass fraction for CASE A. 


\section{CASE B}

CASE C

CAD -89 Temperature

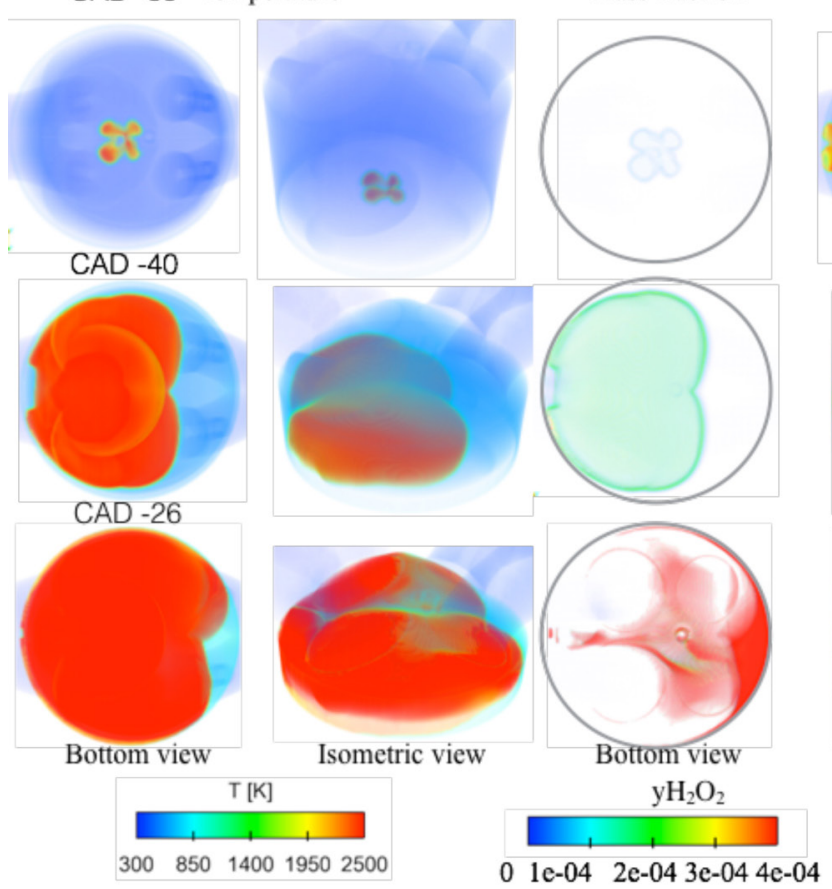

CAD -63.7 Temperature
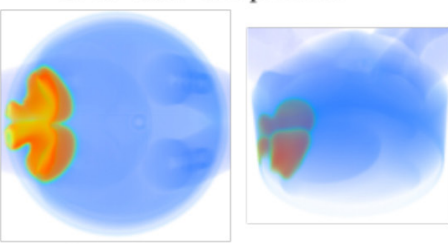

CAD -39

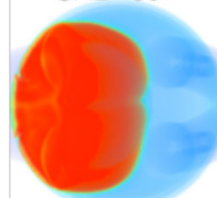

CAD -21.5

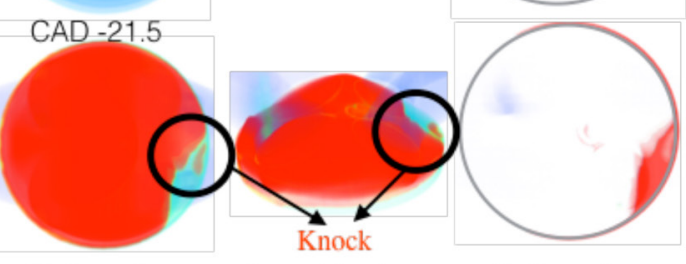

Bottom view Isometric view $T[K]$

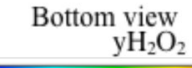

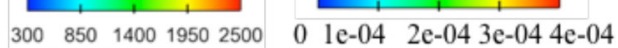

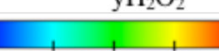

Figure A3. Volume rendered temperature and $\mathrm{H}_{2} \mathrm{O}_{2}$ species formation at various crank angles for CASE B and CASE C.

The Engineering Meetings Board has approved this paper for publication. It has successfully completed SAE's peer review process under the supervision of the session organizer. The process requires a minimum of three (3) reviews by industry experts.

All rights reserved. No part of this publication may be reproduced, stored in a retrieval system, or transmitted, in any form or by any means, electronic, mechanical, photocopying, recording, or otherwise, without the prior written permission of SAE International.

Positions and opinions advanced in this paper are those of the author(s) and not necessarily those of SAE International. The author is solely responsible for the content of the paper.

ISSN 0148-7191

http://papers.sae.org/2017-01-0686 